\title{
ANALISIS PENENTUAN DAYA KVAR UNTUK MENGHINDARI PINALTY PT.PLN (Persero) PADA SAMARINDA CENTRAL PLAZA
}

\author{
Suratno \\ Program Studi Teknik Elektro, Politeknik Negeri Samarinda \\ email : suratnopolnes@gmail.com
}

\begin{abstract}
Abstrak - Untuk mengurangi konsumsi daya reaktif yang besar dapat dilakukan dengan memperbaiki nilai faktor daya. Perbaikan faktor daya dapat dilakukan dengan adanya pemasangan kapasitor bank. Pada Mall Samarinda Central Plaza (SCP), kapasitor yang digunakan dipasang secara paralel yaitu sebesar 2 x $1200 \mathrm{kVAr}$. Faktor daya terendah yang dimiliki sebelum perbaikan yaitu 0,6805 pada bulan Oktober 2017 dan 0,9596 setelah perbaikan faktor daya pada bulan November 2017. Dengan adanya pemasangan kapasitor bank nilai faktor daya dapat menjadi lebih baik atau mendekati angka 1. Selain itu PT. PLN PERSERO juga menetapkan penalty KVAR bila cos phi dibawah 0.86 .
\end{abstract}

Kata Kunci: beban induktif, Kualitas daya listrik, Faktor Daya dan Kapasitor Bank, PLN

\section{PENDAHULUAN}

Umumnya beban di suatu industri kebanyakan bersifat induktif yang mempunyai faktor daya rendah sehingga menyebabkan daya reaktif meningkat dan menyebabkan arus beban yang tinggi sehingga perlu adanya suatu peralatan untuk mengatasi hal tersebut.

Hal ini juga terjadi pada salah satu pusat perbelanjaan di kota Samarinda, yaitu Samarinda Central Plaza (SCP). Telah kita ketahui bahwa di suatu pusat perbelanjaan yang besar terdapat banyak sekali motor-motor listrik yang digunakan. Banyaknya beban beban

tersebut akan mempengaruhi daya reaktif sehingga faktor daya pun ikut terpengaruh. Hal ini dapat menyebabkan faktor daya menjadi rendah atau sangat rendah. Untuk itu dalam memperbaiki faktor daya diperlukan pemasangan kapasitor bank yang tepat pada Samarinda Central Plaza (SCP).

Pada analisa ini akan membahas tentang menentukan kapasitas kapasitor bank yang sesuai dengan kebutuhan beban di SCP. Penentuan ini sangat perlu dilakukan untuk memperbaiki kualitas daya dan mengurangi denda / penalty dari regulasi yang ditetapkan oleh PT.PLN PERSERO.

\section{PERCOBAAN}

Pada gambar 1 dan gambar 2, dapat dilihat data percobaan selama dua bulan dari bulan Oktober sampai dengan bulan Nopember 2017. Pada gambar 1, merupakan data sebelum perbaikan sedangkan pada gambar 2 merupakan data setelah perbaikan.

\begin{tabular}{|c|c|c|c|}
\hline \multirow[t]{2}{*}{ No. } & \multirow[t]{2}{*}{ Tanggal } & LWBP & $\mathrm{kVAR}$ \\
\hline & & $(\mathrm{kW})$ & \\
\hline 1 & 1-Oct-17 & 0,1229 & 0,1204 \\
\hline 2 & 2-Oct-17 & 0,1163 & 0,1125 \\
\hline 3 & 3-Oct-17 & 0,1167 & 0,1162 \\
\hline 4 & $4-$ Oct-17 & 0,1196 & 0,1158 \\
\hline 5 & 5-Oct-17 & 0,1196 & 0,1221 \\
\hline 6 & $6-$ Oct-17 & 0,1229 & 0,1171 \\
\hline 7 & 7 -Oct-17 & 0,1267 & 0,1217 \\
\hline 8 & 8-Oct-17 & 0,1196 & 0,1288 \\
\hline 9 & 9-Oct-17 & 0,1246 & 0,1212 \\
\hline 10 & 10 -Oct-17 & 0,1196 & 0,1175 \\
\hline 11 & 11 -Oct-17 & 0,1254 & 0,1192 \\
\hline 12 & 12 -Oct-17 & 0,1183 & 0,1167 \\
\hline 13 & 13 -Oct-17 & 0,1212 & 0,1183 \\
\hline 14 & $14-$ Oct-17 & 0,1329 & 0,1283 \\
\hline 15 & 15 -Oct-17 & 0,1292 & 0,1254 \\
\hline 16 & 16 -Oct-17 & 0,1271 & 0,1211 \\
\hline 17 & 17 -Oct-17 & 0,1246 & 0,1246 \\
\hline 18 & 18 -Oct-17 & 0,1238 & 0,1167 \\
\hline 19 & $19-$ Oct-17 & 0,1204 & 0,1142 \\
\hline 20 & 20 -Oct-17 & 0,1275 & 0,1212 \\
\hline 21 & 21-Oct-17 & 0,1313 & 0,1208 \\
\hline 22 & 22 -Oct-17 & 0,1329 & 0,1221 \\
\hline 23 & 23 -Oct-17 & 0,1088 & 0,1088 \\
\hline 24 & 24-Oct-17 & 0,1233 & 0,1192 \\
\hline 25 & 25 -Oct-17 & 0,1271 & 0,1225 \\
\hline 26 & 26 -Oct-17 & 0,1238 & 0,1221 \\
\hline 27 & 27 -Oct-17 & 0,1251 & 0,1217 \\
\hline 28 & 28 -Oct-17 & 0,1321 & 0,1311 \\
\hline 29 & 29-Oct-17 & 0,1229 & 0,1271 \\
\hline 30 & 30-Oct-17 & 0,1179 & 0,1113 \\
\hline 31 & 31 -Oct-17 & 0,1233 & 0.1196 \\
\hline
\end{tabular}

Gambar 1. Data Bulan Oktober

Perhitungan Sebelum Perbaikan Faktor Daya pada Instalasi Daya Di SCP

Hal pertama yang harus dilakukan yaitu perhitungan faktor daya dengan kondisi Lewat beban puncak pada bulan Oktober 2017. Lewat beban puncak (LWBP) yaitu pada pukul 22.00 WIB sampai dengan pukul 17.00 WIB.

Data pada bulan Oktober 2017

Dari data pada bab sebelumnya, $\operatorname{Cos} \varphi$ dapat hitung dengan cara : 
$\begin{aligned} \operatorname{Tan} \phi & =\frac{\text { Pemakian } k V A R}{\text { Pemakaian } W B P} \\ \operatorname{Cos} \varphi & =\operatorname{Tan}^{-1} \frac{\text { Pemakian } k V A R}{\text { Pemakaian } W B P}\end{aligned}$

Sebagai contoh, data yang digunakan yaitu data pada tanggal 1 Oktober 2017.

Pemakaian $=\frac{0,1204}{0,1229}=0,98$

Tan $\phi \quad=0,98=0,017$

$\operatorname{Tan}^{-1}=44,41$

Maka $\operatorname{Cos} \varphi=0,7143$

\begin{tabular}{|c|c|c|c|}
\hline \multirow[t]{2}{*}{ No. } & \multirow[t]{2}{*}{ TANGGAL } & LWBP & kVAR \\
\hline & & $(k-W)$ & \\
\hline 1 & 1-Nov-17 & 0,1183 & 0,1163 \\
\hline 2 & 2-Nov-17 & 0,1311 & 0,1225 \\
\hline 3 & 3-Nov-17 & 0,1288 & 0,1204 \\
\hline 4 & 4-Nov-17 & 0,1362 & 0,1321 \\
\hline 5 & 5-Nov-17 & 0,1325 & 0,1325 \\
\hline 6 & 6-Nov-17 & 0,1333 & 0,0808 \\
\hline 7 & 7 -Nov-17 & 0,1342 & 0,0708 \\
\hline 8 & 8-Nov-17 & 0,1392 & 0,0696 \\
\hline 9 & 9-Nov-17 & 0,1304 & 0,0396 \\
\hline 10 & 10-Nov-17 & 0,1383 & 0,0351 \\
\hline 11 & 11-Nov-17 & 0,1346 & 0,0458 \\
\hline 12 & 12-Nov-17 & 0,1304 & 0,0617 \\
\hline 13 & 13-Nov-17 & 0,1267 & 0,0633 \\
\hline 14 & 14-Nov-17 & 0,1351 & 0,0617 \\
\hline 15 & $15-$ Nov- 17 & 0,1411 & 0,0654 \\
\hline 16 & 16-Nov-17 & 0,1388 & 0,0683 \\
\hline 17 & $17-$ Nov-17 & 0,1371 & 0,0617 \\
\hline 18 & 18-Nov-17 & 0,1254 & 0,0451 \\
\hline 19 & 19-Nov-17 & 0,1387 & 0,0629 \\
\hline 20 & 20-Nov-17 & 0,1325 & 0,0604 \\
\hline 21 & 21-Nov-17 & 0,1304 & 0,0617 \\
\hline 22 & 22-Nov-17 & 0,1346 & 0,0613 \\
\hline 23 & 23-Nov-17 & 0,1371 & 0,0637 \\
\hline 24 & 24-Nov-17 & 0,1242 & 0,0579 \\
\hline 25 & 25-Nov-17 & 0,1283 & 0,0621 \\
\hline 26 & 26-Nov-17 & 0,1321 & 0,0629 \\
\hline 27 & $27-$ Nov-17 & 0,1296 & 0,0604 \\
\hline 28 & 28-Nov-17 & 0,1283 & 0,0625 \\
\hline 29 & 29-Nov-17 & 0,1196 & 0,0679 \\
\hline 30 & $30-$ Nov-17 & 0.1358 & 0.0712 \\
\hline
\end{tabular}

Gambar 2. Data Bulan Nopember

Dapat dilihat pada gambar 3, bahwa Cos $\varphi$ di SCP tidak mencapai atau tidak memenuhi nilai $\operatorname{Cos} \varphi$ yang dikatakan baik, yaitu sebesar 0,85 . Besarnya nilai rata-rata $\operatorname{Cos} \varphi$ di Bulan Oktober 2017 yaitu $0,71, \operatorname{Cos} \varphi$ terendah yaitu 0,6805 dan Cos $\varphi$ terbesar yaitu 0,7365.

Data yang digunakan untuk menghitung besarnya kompensasi daya reaktif yaitu pada bulan Oktober 2017, nilai faktor daya terendah yang terjadi pada bulan Oktober 2017 yaitu sebesar 0,6805. Dan daya terpasang pada Mall Samarinda Central Plaza (SCP) adalah 5.540.000 VA

\begin{tabular}{|c|c|c|c|c|c|}
\hline No & Tangeal & KVAK/LWBP & Tan & $\tan ^{-1}$ & $\cos \varphi$ \\
\hline 1 & 1 - 0 est 17 & 0.98 & 0.017 & 44,41 & 0.7143 \\
\hline 2 & $2-0 \mathrm{as}-17$ & 0.97 & 0.017 & 44.06 & 0.7186 \\
\hline 3 & $3-0 x+17$ & 1.00 & 0.017 & 44,90 & $0 . \pi 0 s 4$ \\
\hline 4 & $4-0 \mathrm{~s}-17$ & 0,97 & 0.017 & 44.09 & 0,7183 \\
\hline 5 & $5-9 x-17$ & 1.02 & 0.018 & 45,59 & 0.6998 \\
\hline 6 & $6-0 \mathrm{as}-17$ & 0.95 & 0.017 & 43,61 & 0.7241 \\
\hline 7 & 7 -0es-17 & 0,96 & 0.013 & $43 \times 5$ & 0.7212 \\
\hline 8 & 8-0est 17 & 1,08 & 0.019 & 47,11 & 0.6505 \\
\hline 9 & 2004517 & 0.97 & 0.017 & 44,22 & 0.7160 \\
\hline 10 & $10-0$ as 17 & 0,98 & 0.017 & 44.50 & 0,7133 \\
\hline 11 & $11-0 x-17$ & 0.95 & 0.017 & 43,54 & 0.7249 \\
\hline 12 & $12-0 x-17$ & 0.99 & 0.017 & 44.59 & 0,7121 \\
\hline 13 & $13-0 \mathrm{as}-17$ & 0,98 & 0.017 & 44,30 & 0,7157 \\
\hline 14 & $14-0 \mathrm{ks}-17$ & 0.97 & 0.017 & 43,99 & 0.7194 \\
\hline 15 & $15-0 \mathrm{as}-17$ & 0.97 & 0.017 & 44,16 & 0,7174 \\
\hline 16 & $16-0 \mathrm{ses}-17$ & 0,94 & 0.016 & 43,36 & 0,7271 \\
\hline 17 & 17 - $0 \mathrm{~s}-17$ & 1,00 & 0.017 & 45,00 & 0.7071 \\
\hline 18 & 18 -0st 17 & 0,94 & 0,016 & 43,31 & 0,7276 \\
\hline 19 & 19 -0at-17 & 0.95 & 0.017 & 43,47 & 0.7257 \\
\hline 20 & $20-0 \mathrm{es}-17$ & 0.95 & 0.017 & 43.56 & 0.7246 \\
\hline 21 & 21 - $0 \mathrm{se}-17$ & 0,92 & 0.016 & 42.63 & 0,7357 \\
\hline 22 & $22-0 \times 1.17$ & 0.92 & 0.016 & 42.57 & 0.7364 \\
\hline 23 & $23-0 \mathrm{at}-17$ & 1,00 & 0.017 & 45,00 & 0,7071 \\
\hline 24 & $24+0 \mathrm{as}-17$ & 0.97 & 0.017 & 44,02 & 0,7192 \\
\hline 25 & $25-0 \mathrm{as}-17$ & 0.96 & 0.017 & 43,95 & 0,7200 \\
\hline 26 & $26-0 \mathrm{x}-17$ & 0,99 & 0.017 & 44.61 & 0.7119 \\
\hline 27 & 27 -0xas 17 & 0.97 & 0.017 & 44,23 & 0,7160 \\
\hline 28 & 28 -0est 17 & 0,98 & 0.017 & 44.54 & 0.7127 \\
\hline 29 & 29 ass 17 & 1,03 & 0.018 & 45,95 & 0.0952 \\
\hline 30 & $30-0 \times s-17$ & 0.94 & 0.016 & 43,33 & 0.7274 \\
\hline 31 & $31-0 x-17$ & 0.97 & 0.017 & 44.12 & 0.7179 \\
\hline
\end{tabular}

Gambar 3. Hasil perhitungan bulan Oktober

\begin{tabular}{|c|c|c|c|c|c|}
\hline No & Tanggal & KVAR WBP & $\tan$ & $\tan ^{-1}$ & $\operatorname{Cos} \varphi$ \\
\hline 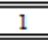 & $\begin{array}{l}\text { 1-Nov-17 } \\
\end{array}$ & 0,98 & 0,017 & 44,49 & 0,7134 \\
\hline 2 & $\begin{array}{l}\text { 2-Nov-17 } \\
\end{array}$ & 0,94 & 0,016 & 43,30 & 0,7278 \\
\hline 3 & $\begin{array}{l}\text { 3-Nov-17 } \\
\end{array}$ & 0,94 & 0 & 443,08 & 0,7303 \\
\hline $\begin{array}{ll}4 \\
\end{array}$ & $\begin{array}{l}\text { 4-Nov-17 } \\
\end{array}$ & 0,97 & 0,017 & 44,11 & 0,7180 \\
\hline 25 & $\begin{array}{l}\text { 5-Nov-17 } \\
\end{array}$ & 1,00 & 0,017 & 45,00 & 0,7071 \\
\hline 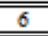 & $\begin{array}{l}\text { 6-Nov-17 } \\
\end{array}$ & 0,61 & 0,011 & 31,23 & 0,8551 \\
\hline $\begin{array}{l}7 \\
\end{array}$ & $\begin{array}{l}\text { 7-Nov-17 } \\
\end{array}$ & 0,53 & 0,009 & 27,83 & 0,8843 \\
\hline 88 & $\begin{array}{l}\text { 8-Nov-17 } \\
\end{array}$ & 0,50 & 0,009 & 26,57 & 0,8944 \\
\hline 99 & $\begin{array}{l}\text { 9-Nov-17 } \\
\end{array}$ & 0,30 & 0,005 & 16,88 & 0,9569 \\
\hline 10 & $\begin{array}{l}10-\text { Nov-17 } \\
\end{array}$ & 0,25 & 0,004 & 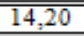 & 0,9695 \\
\hline 111 & $\begin{array}{l}11-N o v-17 \\
\end{array}$ & 0,34 & 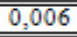 & 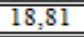 & 0,9466 \\
\hline 1212 & $\begin{array}{l}\text { 12-Nov-17 } \\
\end{array}$ & 0,47 & 0,008 & 25,31 & 0,9040 \\
\hline 13 & $\begin{array}{l}\text { 13-Nov-17 } \\
\end{array}$ & 0,50 & 0,009 & 26,57 & 0,8944 \\
\hline 114 & $\begin{array}{l}\text { 14-Nov-17 } \\
\end{array}$ & 0,46 & 0,008 & 24,55 & 0,9096 \\
\hline 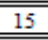 & $\begin{array}{l}15 \text {-Nov-17 } \\
\end{array}$ & $\overline{0,47}$ & 0,008 & 25,04 & 0,9060 \\
\hline 116 & $\begin{array}{l}16-\text { Noy-17 } \\
\end{array}$ & 0,49 & 0,009 & 26,22 & 0,8971 \\
\hline 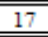 & $\begin{array}{l}17-\text { Nov-17 } \\
\end{array}$ & 0,45 & 0,008 & 24,22 & 0,9120 \\
\hline 18 & 18-Nov-17 & 0,36 & 0,006 & 19,74 & 0,9412 \\
\hline 19 & $\begin{array}{l}\text { 19-Nov-17 } \\
\end{array}$ & 0,45 & 0,008 & 24,39 & 0,9107 \\
\hline 20 & 20-Nov-17 & 0,46 & 0,008 & 24,51 & 0,9099 \\
\hline 21 & $\begin{array}{l}21-\text { Nov-17 } \\
\end{array}$ & 0,47 & 0,008 & 25,31 & 0,9040 \\
\hline 22 & 22-Nov-17 & 0,46 & 0,008 & 24,47 & $0, \frac{0,9102}{2}$ \\
\hline 23 & $\begin{array}{l}23-N o v-17 \\
\end{array}$ & 0,47 & 0 & 24,94 & 0,9067 \\
\hline 24 & $\begin{array}{l}\text { 24-Nov-17 } \\
\end{array}$ & 0,47 & 0,008 & 25,01 & 0,9063 \\
\hline 25 & 25 25-Nov-17 & 0,48 & 0,008 & 25,82 & 0,9002 \\
\hline 26 & 26 -Nov-17 & 0,48 & 0,008 & 25,47 & 0,9028 \\
\hline 27 & $\begin{array}{l}27-\text { Nov- } 17 \\
\end{array}$ & 0,47 & 0,008 & 25,00 & 0,9063 \\
\hline 28 & 28-Nov-17 & 0,49 & 0,009 & 25,97 & 0,8990 \\
\hline 29 & $\begin{array}{l}29-N o v-17 \\
\end{array}$ & 0,57 & 0,010 & 29,59 & 0,8695 \\
\hline 30 & 30-Nov-17 & 0,52 & 0,009 & 27,68 & 0,8856 \\
\hline
\end{tabular}

Gambar 4. Hasil Perhitungan bulan Nopember 
Maka:

$$
\begin{aligned}
\mathrm{S} & =5.540 .000 \mathrm{VA} . \\
\mathrm{P} & =\sqrt{3} \cdot \mathrm{V} \cdot \mathrm{I} \cdot \cos \varphi \\
& =5.540 .000 \cdot 0,6805 \\
& =3.769 .970 \text { watt } \\
Q_{1} & =\sqrt{S^{2}-P^{2}} \\
& =\sqrt{5.540 .000^{2}-3.769 .970^{2}} \\
& =4.059 .424 \mathrm{Var}
\end{aligned}
$$

Dari faktor daya awal yang telah diketahui, untuk menentukan besarnya kapasitor bank yang di pasang yaitu menentukan lebih dulu seberapa besar faktor daya yang digunakan. Karena pada dasarnya faktor daya yang sangat baik adalah 1 , tetapi kenyataan di lapangan atau di industri tidak ada faktor daya yang mencapai 1 . Di sini penulis menentukan besarnya faktor daya yang sudah dikatakan sangat baik yaitu sebesar 0,95 .

Maka:

$$
\begin{aligned}
\mathrm{S} & =5.540 .000 \mathrm{VA} . \\
\mathrm{P} & =\sqrt{3} \cdot \mathrm{V} . \mathrm{I} \cdot \cos \varphi \\
\mathrm{P} & =5.540 .000 \times 0,95 \\
& =5.263 .000 \mathrm{watt} \\
Q_{2} & =\sqrt{5.540 .000^{2}-5.263 .000^{2}} \\
& =1.729 .864,446 \mathrm{Var}
\end{aligned}
$$

Jadi besarnya kompensasi daya reaktif atau kapasitas kapasitor bank yang akan dipasang yaitu:

$$
\begin{aligned}
Q_{c}= & Q_{1}-Q_{2} \\
= & 4.059 .424-1.729 .864,446 \\
= & 2.329 .559,554 \mathrm{VAR} \\
& =2.329,559 \mathrm{kVAR}
\end{aligned}
$$

\section{PEMBAHASAN}

\section{Analisis Perbandingan Faktor Daya Sebelum dan Setelah Perbaikan}

\section{Sebelum Perbaikan Faktor Daya}

Dari data pada gambar 3 didapatkan seperti dibawah ini:

$$
\begin{array}{ll}
\text { Cos } \varphi \text { Terendah } & =0,6805 \\
\text { Cos } \varphi \text { Rata }- \text { Rata } & =0,71 \\
\text { Cos } \varphi \text { Tinggi } & =0,7365 \\
\text { S }=5.540 .000 \text { VA } &
\end{array}
$$

Maka daya aktif pada saat $\cos \varphi$ terendah yaitu:

$$
\begin{aligned}
\mathrm{P}_{1} & =\sqrt{3} \cdot \mathrm{V} \cdot \mathrm{I} \cdot \cos \varphi \\
& =5.540 .000 \cdot 0,68
\end{aligned}
$$

$$
=3.769 .970 \text { watt }=3.769,97 \mathrm{~kW}
$$

Maka daya aktif pada saat $\cos \varphi$ rata - rata yaitu:

$$
\begin{aligned}
\mathrm{P}_{2} & =\sqrt{3} \cdot \mathrm{V} \cdot \mathrm{I} \cdot \cos \varphi \\
& =5 \cdot 540 \cdot 000 \cdot 0,71 \\
& =3.933 \cdot 400 \text { watt }=3.933,4 \mathrm{kw}
\end{aligned}
$$

Maka daya aktif pada saat $\cos \varphi$ tertinggi yaitu:

$$
\begin{aligned}
\mathrm{P}_{3} & =\sqrt{3} \cdot \mathrm{V} \cdot \mathrm{I} \cdot \cos \varphi \\
& =5.540 .000 \cdot 0,7365 \\
& =4.080 \cdot 210 \text { watt }=4.080,21 \mathrm{kw}
\end{aligned}
$$

Maka daya reaktif pada saat $\cos \varphi$ terendah yaitu:

$$
\begin{aligned}
\mathrm{Q}_{1} & =\sqrt{S^{2}-P^{2}} \\
& =\sqrt{5.540 .000^{2}-3.769 .970^{2}} \\
& =4.059 .424 \mathrm{Var}=4.059,42 \mathrm{kVAR}
\end{aligned}
$$

Maka daya reaktif pada saat $\cos \varphi$ rata - rata yaitu:

$$
\begin{aligned}
\mathrm{Q}_{2} & =\sqrt{S^{2}-P^{2}} \\
& =\sqrt{5.540 .000^{2}-3.933 .400^{2}} \\
& =3.901 .277,283 \text { Var }=3.901,28 \\
\mathrm{kVAR} &
\end{aligned}
$$

Maka daya reaktif pada saat $\cos \varphi$ tertinggi yaitu:

$$
\begin{aligned}
\mathrm{Q}_{3}= & \sqrt{S^{2}-P^{2}} \\
= & \sqrt{5.540 .000^{2}-4.080 .210^{2}} \\
= & 3.747 .463,99 \text { Var }=3.747,46 \\
& \text { kVAR }
\end{aligned}
$$

\section{Setelah Perbaikan Faktor Daya}

Dari data pada gambar 4 didapatkan seperti dibawah ini:

$$
\begin{aligned}
& \operatorname{Cos} \varphi \text { Terendah }=0,7071 \\
& \operatorname{Cos} \varphi \text { Rata }- \text { Rata }=0,8760 \\
& \operatorname{Cos} \varphi \text { Tertinggi }=0,9695 \\
& S=5.540 .000 \text { VA }
\end{aligned}
$$

Maka daya aktif pada saat $\cos \varphi$ terendah yaitu:

$$
\begin{aligned}
\mathrm{P}_{1} & =\sqrt{3} \cdot \mathrm{V} \cdot \mathrm{I} \cdot \cos \varphi \\
& =5 \cdot 540 \cdot 000 \cdot 0,7071 \\
& =3 \cdot 917 \cdot 334 \text { watt }=3.917,33 \mathrm{kw}
\end{aligned}
$$

Maka daya aktif pada saat $\cos \varphi$ rata - rata yaitu:

$$
\begin{aligned}
\mathrm{P}_{2} & =\sqrt{3} \cdot \mathrm{V} \cdot \mathrm{I} \cdot \cos \varphi \\
& =5.540 .000 \cdot 0,8760 \\
& =4.853 .040 \text { watt }=4.853,04 \mathrm{kw}
\end{aligned}
$$

Maka daya aktif pada saat $\cos \varphi$ tertinggi yaitu:

$$
\begin{aligned}
\mathrm{P}_{3} & =\sqrt{3} \cdot \mathrm{V} \cdot \mathrm{I} \cdot \cos \varphi \\
& =5 \cdot 540 \cdot 000 \cdot 0,9695
\end{aligned}
$$




$$
=5.371 .030 \text { watt }=5.371,03 \mathrm{kw}
$$

Maka daya reaktif pada saat $\cos \varphi$ terendah yaitu:

$$
\begin{aligned}
\mathrm{Q}_{1} & =\sqrt{S^{2}-P^{2}} \\
& =\sqrt{5.540 .000^{2}-3.917 .334^{2}} \\
& =3.917 .409 \mathrm{Var}=3.917,4 \mathrm{kVAR}
\end{aligned}
$$

Maka daya reaktif pada saat $\cos \varphi$ rata - rata yaitu:

$$
\begin{aligned}
\mathrm{Q}_{2} & =\sqrt{S^{2}-P^{2}} \\
& =\sqrt{5.540 .000^{2}-4.853 .040^{2}} \\
& =2.672 .003 \mathrm{Var}=2.672 \mathrm{kVAR}
\end{aligned}
$$

Maka daya reaktif pada saat $\cos \varphi$ tertinggi yaitu:

$$
\begin{aligned}
\mathrm{Q}_{3}= & \sqrt{S^{2}-P^{2}} \\
= & \sqrt{5.540 .000^{2}-5.371 .030^{2}} \\
= & 1.357 .805,855 \mathrm{Var}=1.357,8 \\
& \text { kVAR. }
\end{aligned}
$$

Dari hasil perhitungan daya aktif, dan daya reaktif sebelum perbaikan dan sesudah diperbaiki dapat dilihat gambar berikut .

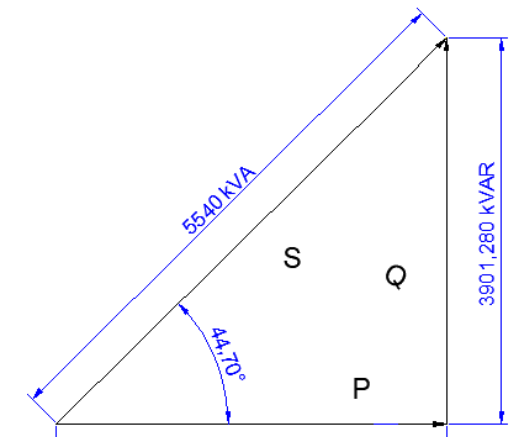

Gambar 5. Segitiga daya saat faktor daya rata-rata sebelum perbaikan

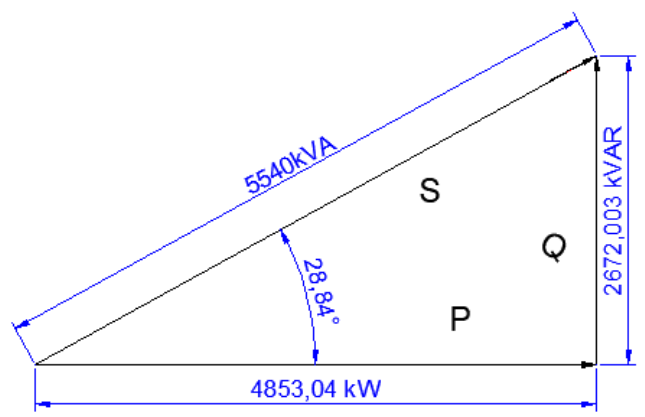

Gambar 6. Segitiga daya saat faktor daya rata-rata setelah perbaikan

\section{KESIMPULAN}

Berdasarkan hasil analisa data pada bab sebelumnya, maka penulis dapat mengambil kesimpulan sebagai berikutL

1. Dari hasil perhitungan didapatkan besarnya kompensasi daya reaktif yang harus diberikan adalah sebesar 2.329,559 kVAR, sehingga akan dipasang kapastor bank $48 \quad$ x 50 kVAR dengan nilai kapasitornya sebesar 308 microFarad.

2. Setelah melakukan perhitungan diketahui faktor daya sebelum dipasang kapasitor bank yaitu sebesar 0,6805 , hal ini membuat kondisi instalasi daya pada mall Samarinda Central Plaza (SCP) memilih faktor daya yang rendah. Kemudian dilakukan perhitungan kompensasi daya reaktif untuk memperbaiki faktor daya, didapatkan kompensasi daya reaktif 2.329,559 kVAR untuk memperbaiki faktor daya yang ada. Serta diketahui kompensasi yang dibutuhkan maka dipasang kapasitor bank untuk memperbaiki faktor daya sehingga didapatkan faktor sebesar 0,9695 dan sudah di diatas batas denda atau penalti PT PLN (0.86).

\section{REFERENSI}

[1] "Pemasangan Kapasitor Bank di Pabrik PT. Eratex Djaja Tbk Probolinggo" Jurnal Iptek Vol.16 No.2 Desember 2012.

[2] "Pengaruh Penambahan Kapasitor Terhadap Tegangan, Arus, Faktor Daya, Dan Daya Aktif Pada Beban Listrik Di Minimarket" Jurnal Teknik Elektro Vol. 9 No. 2 Juli Desember 2017.

[3] "Pemasangan Kapasitor Bank Untuk Perbaikan Faktor Daya" Journal Of Electrical Technology, Vol. 2, No. 3, Oktober 2017.

[4] "Studi Kualitas Listrik Dan Perbaikan Faktor Daya Pada Beban Listrik Rumah Tangga Menggunakan Kapasitor" Journal Singuda Ensikom Vol. 3 No. 2/Agustus 2013

[5] Prayogo Putro Danang Muhammad. Efektifitas Penggunaan Kapasitor Bank Untuk Faktor Daya Pada Batu Night Spectacular (Bns). (Surabaya: Fakultas Teknik Universitas Negeri Surabaya, Ketintang 60231, Indonesia.)

[6] Hardiranto Nur Windu (2017). Analisa Optimasi Perbaikan Faktor Daya Dan Drop Tegangan Dengan Menggunakan Kapasitor 
Bank Pada Line 5 Pt Bukit Asam (Persero) Tbk. (Lampung: Fakultas Teknik Universitas Lampung)

[7] Syawal Putra Rahmat (2015). Analisis Pengaruh Pemasangan Kapasitor Bank Terhadap Faktor Daya (Kendari: Fakultas Teknik Universitas Halu Oleo Kendari)

[8] Bukhari Ahmad Dkk (2012). Perbaikan Power Faktor Pada Konsumen Rumah Tangga Menggunakan Kapasitor Bank. (Bengkalis: Teknik Elektro Jurusanteknik Elektro Politeknik Negeri Bengkalis)

[9] Saragih Tarsin. (2011). Analisis Penempatan Optimal Bank Kapasitor Pada Sistem Distribusi Radial Dengan Metode Genetik Algorithm Aplikasi : Pt. Pln (Persero) Cabang Medan. ( Medan: Fakultas Teknik Universitas Sumatera Utara )

[10] Alto Belly Dkk, (2010), Daya Aktif, Reaktif \& Nyata, ( Jakarta: Universitas Indonesia )5. Seprianti. (2006). Analisis Vibrasi Pada Generator Sinkron. Universitas Sumatera Utara. 